\title{
Familiarity and organization of category terms in semantic memory
}

\author{
DOUGLAS J. HERRMANN \\ Hamilton College, Clinton, New York 13323 \\ and \\ BARBARA E. KAY \\ Kirkland College, Clinton, New York 13323
}

\begin{abstract}
In order to determine production frequencies for various category terms, 219 college students were asked to generate category terms (e.g. Automobiles, Vegetables, Relatives) during a 4-min period. The production frequency (i.e., the number of subjects who listed a particular term) for a given category term may be considered as reflecting the familiarity or amount of usage of that category term, and, as such, should be of value to memory researchers in designing experiments. Additionally, examination of the order in which terms were produced showed that subjects "clustered" related category terms, (e.g., "Countries" and "States" were often produced successively). This clustering of category terms is supportive of the hypothesis that categories are organized in semantic memory in some kind of higher order structure.
\end{abstract}

Research employing words from taxonomic categories (e.g., animals, foods) has figured prominently in work on human memory for over 20 years. For example, numerous studies have been concerned with the role of category organization in free recall learning (Kausler, 1974; Shuell, 1969; Tulving \& Donaldson, 1972). Also, considerable work has recently been directed at elucidating which factors affect comprehension of category membership (Collins \& Loftus, 1975; Perfetti, 1972; Smith, Rips, \& Shoben, 1974). Investigators in both of these research areas have typically used categories selected from one of the existing category-word norms (Battig \& Montague, 1969; Hunt \& Hodge, 1971; Loess, Brown, \& Campbell, 1969; Shapiro \& Palermo, 1970; Cohen, Bousfield, \& Whitmarsh, Note 1). These categoryword norms present various category terms and, for each category, a list of words which subjects report to be examples of the category. One would hope that the categories used in the various norms represent the most common or most typical categories in the language. Nevertheless, with one exception (Shapiro \& Palermo, 1970), none of the published norms state a precise criterion by which categories were selected for inclusion in the norms. Moreover, none of the norms report evidence that the categories therein are representative of what subjects would regard as categories, or which categories are most familiar to subjects. With the exception noted above, all developers of category-word norms

We wish to thank Sandra DeMyer-Gapin, Carolyn B. Mervis, and Jonathan Vaughan for valuable advice on an earlier draft of this article. Requests for reprints should be sent to Douglas J. Herrmann, Department of Psychology, Hamilton College, Clinton, New York 13323. appear to have used intuition as the criterion for selecting those categories used in the norms. While it is possible that the intuitions of norm-developers were successful in selecting predominantly familiar categories, this remains to be empirically verified. Consequently, the principal purpose of the present research was to determine which category terms, that is, superordinate labels, are the most common. The commonality of category frequency is potentially important experimentally since commonality of stimuli has long been known to affect performance in many cognitive tasks (Hall, 1970; Smith, 1968; Wilkins, 1971; Woodworth \& Schlosberg, 1954).

In the present study, the procedure for ascertaining which category labels are most common in the language was simply to ask subjects to write down, within a limited time period, names of common categories. The category-term responses were then tabulated and rank ordered from most frequently produced to least frequently produced, thus allowing easy determination of the most common categories.

A second purpose of the study was to determine whether there is any consistency in the order of production of category labels across subjects. Bousfield and Sedgewick (1944) found that when subjects produced examples of a category (e.g., birds) they tended to produce words in conceptually common clusters (e.g., parrot, canary, parakeet). Similarly, the present study examined subject protocols for evidence of successive recall of category terms which are related (e.g., birds, animals, fish). Evidence of clustering of category terms would support recent research indicating a higher order structure of categories in semantic memory (Collen, Wickens, \& Daniele, 1975; Herrmann, Shoben, Klun, \& Smith, 1975). 


\section{METHOD}

\section{Subjects}

A group of 136 males from Hamilton College and 92 females from Kirkland College participated in the experiment. (Hamilton and Kirkland Colleges are small, private, liberal arts institutions.) Students from several classes were asked by their instructors to participate either during or following classes. Students were free to choose not to participate and approximately 20 elected not to do so. The lower number of females was a consequence of Kirkland's enrollment's being two-thirds as large as that of Hamilton, with class composition reflecting this ratio. Five females and four males were excluded from the analysis due to their misinterpreting directions, as evidenced by listing exemplars of categories as well as the category terms. Thus, 132 males and 87 females constituted the final sample of subjects.

\section{Procedure}

Subjects participated in the study during either the first or last $12 \mathrm{~min}$ of class or, for two classes, for $12 \mathrm{~min}$ after class. Classes ranged in size from approximately 12 to 28 students, with a mean of approximately 20 students. Large lecture sections were not used for two reasons. First, the directions for the category-term production task included an example of a category term to insure that subjects knew what was meant by "category term." Use of a particular label with a large class would have biased the frequency with which subjects produced that category. To minimize such bias, a particular example of a category label was used in no more than 2 out of the 12 classes sampled. A second reason for using several small classes was to obtain a total sample composed of students from many disciplines, rather than only from psychology. Thus, the 12 classes comprising the total sample included 5 which represented departments other than psychology. Moreover, of the seven psychology classes, five were at an introductory level and consequently included many nonpsychology majors. Only two classes were constituted solely of psychology majors.

After an appeal for cooperation by the class professor, subjects were asked to perform a category generation task. A category was defined as being "a word or set of words which refer to another group of words which share some common characteristic." Following this definition, an example of a category term and two of its members was given to the different classes in the experiment. The examples were "Automobiles (Buick, MG)," "Motorcycles (Yamaha, Harley Davidson)," "Illnesses (flu, polio)," "A Type of Behavior-Modification Therapy (extinction, reinforcement)," "A Style of House (Tudor, splitlevel)," "Relatives (mother, uncle)," "A Type of Government (fascist, democracy)," and "Famous Artists (Van Gogh, Picasso)." After the explanation of category terms, subjects were directed to write as many examples as possible of "common" category terms in a 4-min period.

\section{RESULTS AND DISCUSSION}

\section{Adequacy of Category-Term Generation}

Response protocols were inspected to determine if instructions were understood by subjects. One objective criterion for comprehension of instructions was the production by a subject of at least one category term used in category norms (Battig \& Montague, 1969; Hunt \& Hodge, 1971; Loess et al., 1969; Shapiro \& Palermo, 1970; Cohen et al., Note 1). By this criterion, $100 \%$ of the females and $95 \%$ of the males understood the directions. Of the remaining six males, the authors judged responses of only two subjects as being composed entirely of words not commonly regarded as categories (e.g., adjectives such as "rich, good, easy").

\section{Commonality of Category Terms}

The average number of category terms produced by a subject in the 4-min period was approximately 28 terms. Table 1 presents commonality data for the different category terms generated by subjects. The first column of Table 1 presents category terms numbered in descending rank order of production frequency, that is, the number of subjects producing the category term. Responses produced by only one or two subjects are not presented in the table in order to save space (there were 141 responses produced twice and 1,123 produced once). Investigators who wish to have a list of the lowfrequency terms may obtain a copy from the authors. In a few cases, there are two or more category terms grouped under one category-term number. This is because in these instances the different category terms appeared to be referring to the same class of exemplars. However, since some readers might disagree with the present authors' judgment of synonymy between different category terms, where different category terms are grouped together, the relevant statistics for each of the terms are also presented separately.

The second column lists for each term the total number of subjects who produced the term, that is, its frequency (f) and the number of subjects who listed the term first (1st) in their 4-min production. For items which are actually a composite of two or more different responses judged to be synonymous, the count for each of the separate terms is listed within parentheses. For example, the responses "car" and "automobile" were grouped together (Category Term 2 in Table 1). The statistics given in the second column indicate that a total of 129 subjects generated the two terms; that 103 subjects produced "car" and 26 produced "automobile"; that 16 subjects gave these terms first; and, that 9 subjects gave "car" first and 7 subjects gave "automobile" first.

\section{Reliability of Commonality Measures}

Two reliability measures were calculated on the frequency data. First, a split-level reliability coefficient was determined. This was done by dividing the total sample into two groups containing an equal number of males and females and then correlating the groups on the production frequency of those terms with a frequency of three or above in either group. The correlation was $r=.895(p<.001)$, and can be compared to the intersample correlation in the Battig and Montague (1969) norms. For each category (e.g., bird), Battig and Montague correlated the number of times each word was produced as an example of the category (e.g., sparrow, canary) in each of two samples, for all words produced by 10 subjects or more across both samples. Across 56 categories, the intersample correlation ranged from .097 to .997 , with a median correlation of .967 . Thus, it is seen that the present reliability was somewhat less than that typically found for production within a category, but the reliability was not nearly as low as has been found for production within some categories. 
Table 1

Category Terms, Produced by 219 Subjects, Listed in Order of Decreasing Frequency (f)

\begin{tabular}{|c|c|c|c|c|c|}
\hline Category Term & Total f; f of 1 st & $\begin{array}{c}\text { Norms } \\
\text { Using Term* }\end{array}$ & Category Term & Total $f ; f$ of 1 st & $\begin{array}{l}\text { Norms } \\
\text { Using Term* }\end{array}$ \\
\hline 1. clothing, clothes, apparel & $\begin{array}{l}150(101,30,19) \\
14(14,0,0)\end{array}$ & $\mathrm{C}, \mathrm{B}, \mathrm{L}, \mathrm{H}$ & $\begin{array}{l}\text { 57. professors } \\
\text { 58. writing implements, }\end{array}$ & $\begin{array}{l}20 \\
19(8,1,7,2,1)\end{array}$ & $\mathbf{S}$ \\
\hline 2. car, automobile & $\begin{array}{l}129(103,26) \\
16(9,7)\end{array}$ & $\mathbf{L}, \mathbf{H}$ & $\begin{array}{l}\text { writing articles, writing } \\
\text { utensils, writing objects, }\end{array}$ & $1(1,0,0,0,0)$ & \\
\hline 3. books & $102 ; 15$ & & writing tools & & \\
\hline 4. sports & $88 ; 16$ & $\mathrm{C}, \mathrm{B}, \mathrm{L}, \mathrm{H}$ & 59. days, days of the week & $19(15,4)$ & $\mathbf{S}, \mathbf{H}$ \\
\hline 5. foods & $82 ; 2$ & & 60. records & 19 & \\
\hline 6. trees & $78 ; 5$ & $\mathrm{C}, \mathrm{B}, \mathbf{L}, \mathrm{H}$ & 61. shirts & 19 & \\
\hline 7. animals & $77 ; 1$ & & 62. hair styles & $18 ; 1$ & \\
\hline 8. people, persons, humans & $\begin{array}{l}74(41,23,10) \\
6(4,0,2)\end{array}$ & & $\begin{array}{l}\text { 63. teachers } \\
\text { 64. TV shows, TV programs }\end{array}$ & $\begin{array}{l}18 \\
18(14,4)\end{array}$ & $\mathbf{H}$ \\
\hline 9. houses, homes & $65(47,18) ; 1(1,0)$ & B,L,H & 65. watches & 18 & \\
\hline 10. colors & $64 ; 8$ & $\mathrm{C}, \mathrm{B}, \mathrm{H}$ & 66. cigarettes & $17 ; 1$ & \\
\hline 11. shoes & $62 ; 2$ & $\mathrm{C}, \mathrm{B}, \mathrm{H}$ & 67. jewelry & 17 & $\mathbf{S}$ \\
\hline 12. buildings & $60 ; 2$ & $\mathrm{~S}$ & 68. students & $17 ; 1$ & \\
\hline 13. countries, nations & $59(51,8) ; 3(2,1)$ & $\mathbf{C}, \mathbf{B}, \mathbf{L}, \mathbf{S}, \mathbf{H}$ & 69. bodies & 16 & \\
\hline 14. furniture & $58 ; 3$ & $\mathrm{C}, \mathbf{B}, \mathrm{H}$ & 70. sciences & 16 & $\mathrm{C}, \mathrm{B}, \mathrm{H}$ \\
\hline 15. dogs & $47 ; 5$ & & 71. subjects & 16 & \\
\hline 16. schools & $43 ; 3$ & $\mathrm{~B}$ ?, H? & 72. words & $16 ; 1$ & \\
\hline $\begin{array}{l}\text { 17. courses, school subjects, } \\
\text { subjects of class }\end{array}$ & $42(40,1,1) ; 2(2,0)$ & $\mathrm{S}$ & $\begin{array}{l}\text { 73. letters of alphabet, } \\
\text { alphabet }\end{array}$ & $15(12,3) ; 1(1,0)$ & \\
\hline 18. plants & $42 ; 3$ & & 74. paintings & 15 & \\
\hline 19. games & $41 ; 1$ & $\mathbf{H}$ & 75. personalities & 15 & \\
\hline 20. art, art forms, arts & $40(24,14,2)$ & & 76. roads, streets & $15(10,5)$ & \\
\hline 21 , cities & 38 & $\mathbf{B}, \mathbf{H}$ & 77. wood & 15 & $\mathbf{S}$ \\
\hline 22. movies, flicks & $38 ; 1$ & & 78. architecture & 14 & \\
\hline 23. fruit & $37 ; 4$ & C,B,H & 79. fraternities & 14 & \\
\hline 24. body, part of; anatomy & $35(21,14) ; 4(4,0)$ & C,B,, $\mathbf{L}$ & 80. insects & $14 ; 1$ & $\mathrm{C}, \mathrm{B}, \mathrm{L}, \mathrm{H}$ \\
\hline 25. emotions, feelings & $34(18,16) ; 2(2,0)$ & $\mathrm{S}, \mathrm{H}$ & 81. mammals & 14 & \\
\hline 26. flowers & $34 ; 1$ & $\mathrm{C}, \mathbf{B}, \mathbf{L}, \mathrm{H}$ & 82. months & 14 & $\mathbf{S}$ \\
\hline 27. chairs & 33 & & 83. motorcycles & $14 ; 1$ & \\
\hline 28. planes; airplanes & $33(18,15) ; 2(2,0)$ & & 84. rugs & 14 & \\
\hline 29. states, states of U.S. & $33(32,1) ; 1(1,0)$ & $\mathrm{B}, \mathbf{L}, \mathbf{H}$ & 85. dances, dancing & 13 & $\mathrm{C}, \mathrm{B}, \mathrm{H}$ \\
\hline 30. weather & 33 & $\mathbf{C}, \mathbf{B}, \mathbf{L}, \mathbf{H}$ & 86. entertainment & 13 & \\
\hline 31. girls, women, females & $\begin{array}{l}32(17,13,2) \\
2(2,0,0)\end{array}$ & & $\begin{array}{l}\text { 87. governments } \\
\text { 88. machines }\end{array}$ & $\begin{array}{l}13 ; 1 \\
13\end{array}$ & \\
\hline 32. vegetables & $31 ; 1$ & C,B,L & 89. socks & 13 & \\
\hline 33. jobs & 30 & $\mathrm{C} ?, \mathrm{~B} ?, \mathrm{~L} ?, \mathrm{H}$ ? & 90. tests, exams & $13(7,6)$ & \\
\hline 34. music & $30 ; 3$ & B & 91. doctors & $12 ; 2$ & \\
\hline 35. colleges, univer sities & $29(26,3) ; 2$ & $\mathrm{~B}, \mathrm{H}$ & 92. dorm, dormitory & $12(8,4) ; 1(0,1)$ & \\
\hline $\begin{array}{l}\text { 36. religions, religious sects, } \\
\text { church denominations }\end{array}$ & $29(27,1,1) ; 1$ & S & $\begin{array}{l}\text { 93. grass } \\
\text { 94. materials }\end{array}$ & $\begin{array}{l}12 \\
12\end{array}$ & \\
\hline 37. drinks, beverages & $28(19,9)$ & $\mathbf{H}$ & 95. men, males, man & $12(9,2,1) ; 2(2,0,0$ & \\
\hline 38. boats & $26 ; 2$ & & 96. numbers & $12 ; 1$ & $\mathbf{S}$ \\
\hline 39. disease, illness, sickness & $\begin{array}{l}26(11,8,7) \\
3(2,1,0)\end{array}$ & $\mathrm{C}, \mathrm{B}, \mathrm{L}, \mathrm{H}$ & $\begin{array}{l}\text { 97. reptiles } \\
\text { 98. smells, odors, scents }\end{array}$ & $12(7,4,1)$ & $\mathrm{S}$ \\
\hline 40. language, foreign language & $26(25,1)$ & $\mathbf{S}$ & 99. textures & 12 & \\
\hline 41. papers & 26 & & 100. trucks & 12 & \\
\hline 42. rooms & 26 & & 101. work; physical work & $12(11,1)$ & \\
\hline 43. stores, shops & $26(25,1) ; 1$ & & 102. educations & $11 ; 1$ & \\
\hline 44. bicycles, bikes & $25(23,2)$ & & 103. money, currency & $11(9,2)$ & B \\
\hline 45. cats & $25 ; 2$ & & 104. oceans & 11 & $\mathbf{S}, \mathrm{H}$ \\
\hline 46. classes & 25 & & 105. pants & 11 & \\
\hline 47. pens & 24 & & 106. relatives, members of & $11(6,2,1,1,1)$ & $\mathrm{B}, \mathrm{H}$ \\
\hline 48. birds & $23 ; 3$ & $\mathrm{C}, \mathrm{B}, \mathbf{L}, \mathrm{H}$ & family, family members, & $1(0,1,0,0,0)$ & \\
\hline 49. fish & 23 & $\mathrm{C}, \mathrm{B}, \mathrm{L}, \mathrm{H}$ & family relations, relations & & \\
\hline 50. friends & $23 ; 1$ & & 107. lights & 10 & \\
\hline 51. occupations, professions, & $23(10,7,4,1,1)$ & $\mathbf{C}, \mathbf{B}, \mathbf{L}, \mathbf{H}$ & 108. literature & 10 & \\
\hline careers, career choices, & & & $\begin{array}{l}\text { 109. meat } \\
110 . \text { medicine }\end{array}$ & $\begin{array}{l}10 ; 1 \\
10\end{array}$ & $\mathrm{~S}, \mathrm{H}$ \\
\hline 52. races racial groups, & $22(18,3,1)$ & $\mathbf{H}$ & $\begin{array}{l}\text { 110. medicine } \\
111 . \text { newspapers }\end{array}$ & 10 & \\
\hline $\begin{array}{l}\text { 52. races, racial groups, } \\
\text { races of people }\end{array}$ & $1(1,0,0)$ & & 112. parties & 10 & H? \\
\hline 53. sex & $22 ; 2$ & & 113. rivers, names of rivers & $10(9,1)$ & \\
\hline 54. beer & 20 & & 114. ship & 10 & $\mathbf{C}, \mathbf{B}, \mathbf{L}, \mathbf{H}$ \\
\hline 55. hair & 20 & & 115. sizes & 10 & \\
\hline 56. magazines & 20 & $\mathbf{H}$ & 116. songs & 10 & \\
\hline
\end{tabular}


Table 1 continued -

\begin{tabular}{|c|c|c|c|c|c|}
\hline Category Term & Total f; f of 1st & $\begin{array}{c}\text { Norms } \\
\text { Using Term* }\end{array}$ & Category Term & Total f; f of $1 \mathrm{st}$ & $\begin{array}{c}\text { Norms } \\
\text { Using Term* }\end{array}$ \\
\hline 117. study, studying, studies & $10(3,3,4)$ & & 182. exercise & 6 & $\mathbf{S}$ \\
\hline 118. tools & 10 & $\mathbf{H}$ & 183. good, goodness & $6(4,2)$ & \\
\hline 119. transportation & 10 & & 184. grades & 6 & \\
\hline 120. vehicles & 10 & $\mathrm{C}, \mathrm{B}$ & 185. horses & 6 & \\
\hline 121. water & 10 & & 186. ideas & $6 ; 1$ & \\
\hline 122. car, parts of & 9 & $\mathbf{S}$ & 187. instruments & 6 & B?, L?, S?, \\
\hline 123. lakes & 9 & & 188 libraries & 6 & \\
\hline 124. mountains & 9 & & & & \\
\hline 125. musical instruments & 9 & $\mathrm{C}, \mathrm{B}, \mathrm{L}, \mathrm{H}$ & 189. life styles, style of living & $6(5,1)$ & \\
\hline 126. nationalities, ethnic & $9(6,2,1)$ & & 190. liquids & 6 & $\mathbf{S}$ \\
\hline groups, ethnic minorities & & & 191. plays & 6 & \\
\hline 127. philosophies & 9 & & 192. relationships & 6 & \\
\hline 128. rock & $9 ; 2$ & & 193. rings & 6 & \\
\hline 129. speech & 9 & & 194. typewriters & 6 & \\
\hline 130. tables & 9 & & 195. wars & 6 & $\mathbf{H}$ \\
\hline 131. alcohol & $8 ; 1$ & $\mathrm{C} ?, \mathrm{~B} ?$ & 196. alcoholic beverages & 5 & $\mathrm{C}, \mathrm{B}$ \\
\hline 132. authors, writers & $8(6,2)$ & & 197. amphibians & 5 & \\
\hline 133. carpet & 8 & & 198. backpacks & 5 & \\
\hline 134. chemicals & 8 & & 199. balls & 5 & \\
\hline 135. clocks & 8 & & 200. bars, taverns & $5(3,2) ; 1$ & \\
\hline 136. clouds & 8 & & 201. beds & 5 & \\
\hline 137. desks & 8 & & 202. business & 5 & \\
\hline 138. family & $8 ; 1$ & & 203. churches & 5 & $\mathrm{C} ?, \mathrm{~B}$ ? \\
\hline 139. footwear & 8 & $\mathrm{C}, \mathrm{B}, \mathrm{H}$ & 204. cooking utensils & 5 & \\
\hline 140. haircolor & 8 & & 205. dates, dating & $5(4,1)$ & \\
\hline 141. hats & 8 & & 206. dresses & 5 & \\
\hline 142. ice cream & 8 & $\mathbf{S}$ & 207. eating u tensils & 5 & $\mathbf{S}$ \\
\hline 143. institutions & $8 ; 1$ & & 208. floors & 5 & \\
\hline 144. land, terrain, ground & $8(4,3,1)$ & & 209. guitar & 5 & \\
\hline 145. metals & 8 & $\mathrm{C}, \mathrm{B}, \mathrm{H}$ & 210. high school & 5 & \\
\hline 146. minerals & 8 & $\mathbf{H}$ & 211. history & 5 & \\
\hline 147. mountains & 8 & $\mathbf{H}$ & 212. hobbies & 5 & \\
\hline 148. names & 8 & & 213. industry & 5 & \\
\hline 149. places & 8 & & 214. jackets & 5 & \\
\hline 150. planets & 8 & $\mathrm{~S}, \mathrm{H}$ & & $5(3,1,1)$ & \\
\hline $\begin{array}{l}151 . \text { radio } \\
152 \text {. seasons }\end{array}$ & $\begin{array}{l}8 \\
8\end{array}$ & & $\begin{array}{l}\text { Kirkette } \\
\text { 216. lamps }\end{array}$ & & \\
\hline $\begin{array}{l}\text { 152. seasons } \\
\text { 153. shapes }\end{array}$ & $\begin{array}{l}8 \\
8\end{array}$ & $\mathrm{~S}, \mathrm{H}$ & $\begin{array}{l}\text { 216. lamps } \\
217 . \text { liquor }\end{array}$ & $\begin{array}{l}5 \\
5\end{array}$ & C?,B?,S \\
\hline 154. stereos & 8 & & $\begin{array}{l}\text { 217. liquor } \\
218 . \text { maps }\end{array}$ & $\begin{array}{l}5 \\
5\end{array}$ & \\
\hline 155. thoughts & 8 & & 219. mathematics & 5 & \\
\hline 156. toothpaste & $8 ; 2$ & & 220. paints & 5 & \\
\hline 157. utensils & 8 & & 221. politician & 5 & \\
\hline 158. windows & 8 & & 222. presidents of the U.S., & $5(3,2)$ & $\mathbf{L}$ \\
\hline 159. beaches & 7 & & presidents & & \\
\hline 160. cloth, fabric & $7(5,2)$ & $\mathrm{C}, \mathrm{B}, \mathrm{L}$ & 223. solids & 5 & \\
\hline 161. continents & $7 ; 1$ & $\mathbf{H}$ & 224. tastes & 5 & \\
\hline 162. eye color, eyes & $7(4,3)$ & & 225. transportation vehicles & 5 & \\
\hline 163. glasses & 7 & & 226. water bodies & 5 & \\
\hline 164. mail & 7 & & 227 . actors & 4 & \\
\hline 165. meals & 7 & $\mathbf{H}$ & 228. age & 4 & \\
\hline 166. moods & 7 & & 229. airline companies, airlines & $4(3,1)$ & \\
\hline 167. poems, poetry & $7(6,1)$ & & 230. appliances & 4 & \\
\hline 168. restaurants & 7 & & 231. bad & 4 & \\
\hline 169. silverware & 7 & & 232. biology & 4 & \\
\hline 170. soap & 7 & & 233. blood, blood types & $4(3,1)$ & \\
\hline 171. toys & 7 & B & 234. breakfast cereal, cereal & $4(3,1)$ & \\
\hline 172. travel & 7 & & 235. categories & 4 & \\
\hline 173. TV, television & $7(4,3)$ & & 236. cigar & 4 & \\
\hline 174. vacations & 7 & & 237 . classrooms & 4 & \\
\hline 175. wine & 7 & & 238. cosmetics & 4 & $\mathrm{H}$ \\
\hline 176. writing, writing styles & $7(4,3)$ & & 239. cultures & 4 & \\
\hline 177. athletes & $6 ; 1$ & & 240. death, modes of death & $4(3,1)$ & \\
\hline 178. candy & 6 & & 241. dreams & 4 & \\
\hline 179. children & 6 & & 242. enemies & 4 & \\
\hline 180. ceiling & 6 & & 243. experiments & 4 & \\
\hline 181. counties & 6 & & 244. gases & 4 & \\
\hline
\end{tabular}


Table 1 continued-

\begin{tabular}{|c|c|c|}
\hline Category Term & Total $\mathrm{f} ; \mathrm{f}$ of $1 \mathrm{st}$ & $\begin{array}{c}\text { Norms } \\
\text { Using Term* }\end{array}$ \\
\hline 245. guns & 4 & \\
\hline 246. islands & 4 & $\mathbf{H}$ \\
\hline 247 . jogging, running & $4(2,2)$ & \\
\hline 248. labor & 4 & H? \\
\hline 249 . leaves & 4 & \\
\hline 250. living quarters & 4 & $\begin{array}{l}\text { C?, B?, L?, } \\
\mathrm{H} \text { ? }\end{array}$ \\
\hline 251. musicians & $4 ; 1$ & \\
\hline 252. pencils & 4 & \\
\hline 253. sculpture & 4 & \\
\hline 254. seasoning, spices & $4(2,2)$ & $\mathbf{S}$ \\
\hline 255 . shells & 4 & \\
\hline 256. shrubs & 4 & \\
\hline 257. species & 4 & \\
\hline $\begin{array}{l}\text { 258. sports equipment, } \\
\text { sporting goods }\end{array}$ & $4(3,1)$ & $\mathbf{S}$ \\
\hline 259. stars & 4 & $\mathbf{H}$ \\
\hline 260. stories & 4 & \\
\hline 261. triangle & 4 & \\
\hline 262. walls & 4 & \\
\hline 263. years & 4 & \\
\hline 264. activity & 3 & $\mathbf{S}$ \\
\hline 265. barns & 3 & \\
\hline 266. bases & 3 & \\
\hline 267. capitols, capitol cities & $3(2,1) ; 1(0,1)$ & \\
\hline 268. centuries & 3 & \\
\hline 269. characters & 3 & \\
\hline 270. composers & 3 & $\mathrm{~S}, \mathrm{H}$ \\
\hline 271. concerts & 3 & \\
\hline 272. English & 3 & \\
\hline 273. freaks & 3 & \\
\hline 274. habit & 3 & \\
\hline 275. happy & 3 & \\
\hline 276. hippies & 3 & \\
\hline 277. hospitals & 3 & \\
\hline 278. kinds of books & 3 & \\
\hline 279. love & 3 & \\
\hline 280. moose & 3 & \\
\hline 281 . organizations & 3 & \\
\hline 282. pets & 3 & $\mathbf{S}$ \\
\hline 283. plates & 3 & \\
\hline 284. play & 3 & \\
\hline 285. pre-meds & 3 & \\
\hline 286. runners, joggers & $3(2,1)$ & \\
\hline $\begin{array}{l}\text { 287. Senators of the U.S., } \\
\text { senators }\end{array}$ & $3(2,1)$ & \\
\hline 288. sexes & 3 & \\
\hline 289. shampoos & 3 & \\
\hline 290. shows & 3 & \\
\hline 291. sinks & 3 & \\
\hline 292. snakes & 3 & $\mathrm{C}, \mathrm{B}$ \\
\hline 293. snow & 3 & \\
\hline 294. soft & 3 & \\
\hline 295. sources of energy, energy & $3(2,1)$ & \\
\hline 296. streams & 3 & \\
\hline 297. supermarkets & 3 & \\
\hline 298. time & $3 ; 1$ & \\
\hline 299. underwear & 3 & \\
\hline 300 . weights & 3 & \\
\hline
\end{tabular}

Note-Numbers in parentheses represent individual category terms which have been grouped together in Column 1. No entry occurs in the table for a first-production frequency of zero. *The letters in this column represent the following category norms: Cohen et al., 1957 (C), Battig and Montague, 1969 (B), Loess et al., 1969 (L), Shapiro and Palermo (S), and Hunt and
Hodge (H). A "?" by a norms symbol indicates that the interpretation of the term produced here as being the same as the category listed in that norm is questionable.

Second, the production frequencies of females was correlated with that of males $(r=.864, p<.001$, for terms with a total frequency of three or more). The correlation between males and females was significantly lower than that for the split-half correlation $(z=1.68$, $p<.05$, one-tailed test). A one-tailed test was used because the correlation of frequencies across sex groups should be no better than, and possibly worse than, the reliability coefficient between sample halves equated for representation of the sexes. However, the magnitude of variance accounted for by sex differences was obviously low (5.5\%), and, therefore, sex differences were probably important for only a small number of category terms. (A breakdown of the frequency data in Table 1 according to the sex of subjects is available from the authors.)

\section{Commonality of Category Terms in Category-Word Norms}

The third column indicates which category-word norms included the particular category term. Norms which used the term, or a clear synonym of the term, are each symbolized by a different capital letter (see footnote to Table 1). Responses which may or may not be equivalent to categories in a norm (depending on interpretation of a category term) are listed with a "?" beside the capital letter. The norms symbols are presented in Table 1 for two reasons. First, presentation of norms symbols in the table permits a quick conclusion as to whether or not production frequency covaries with past usage of categories in norms. Second, the symbols provide an index of which norms might be consulted by experimenters who wish to use a particular category.

Examination of the third column of Table 1 indicates that the likelihood of a category's inclusion in a norm increased directly with the term's frequency in the present data. When past norms are compared in Table 1, it appears that all of the previous norms employed many rare categories. Fifteen of the 43 categories in the Cohen et al. (Note 1) norms do not appear in Table 1, that is, these terms were not produced by three or more of the present subjects. Similarly, 22 categories of the 56 in the Battig and Montague (1969) norms (which includes the 43 in the Cohen et al. norms), 10 categories of the 30 categories in the Loess et al. (1969) norms (which included 26 of the 43 categories from the Cohen et al. norms), 72 of the 100 categories in the Shapiro and Palermo (1970) norms, and 36 of the 84 categories in the Hunt and Hodge (1971) norms (which includes 31 categories in the Cohen et al. norms), also do not appear in Table 1. Thus, at least $33 \%$ of the category terms in any of the category-word norms are uncommon when usage is estimated by Table 1 . No 
attempt was made to assess which norms might be most representative of the population of categories, due to complexities involved in establishing an acceptable criterion of representativeness.

\section{Clustering of Category Terms}

The second purpose of the present study had to do with the sequence in which subjects produced category terms. Examination of individual protocols showed a tendency for subjects to recall related categories together. For example, of the 30 subjects who produced just two geographic terms (e.g., cities, continents, counties, countries, states) during the 4-min period, 23 subjects recalled the terms successively. Of the 12 subjects who produced three geographic terms, 8 subjects recalled all three in succession and 4 subjects recalled two of the three terms in succession. Only three subjects generated four geographic terms; all three subjects recalled the terms successively. Given that the average number of terms produced was 28 , all of the above clusters are highly significant $(p<.001)$ according to combinatorial principles and the binomial expansion. Many other groupings of semantically similar categories were observed in subjects' protocols (e.g., transportation category terms and categories of things to eat). Thus, subjects "cluster" category terms in the same manner as observed by Bousfield and Sedgewick (1944) for production of examples within a category. Structure in the recall of category terms is consistent with recent evidence of higher order organization of categories in semantic memory, based on sorting data (Collen et al., 1975; Herrmann et al., 1975).

\section{Importance of Controlling Category Familiarity}

Stimulus familiarity is well known to affect learning (Hall, 1971), association (Woodworth \& Schlosberg, 1954), categorization (Wilkins, 1971), and other information processing tasks (Smith, 1968). If category familiarity is not controlled across experimental conditions, then familiarity may inadvertently become confounded with conditions. Such a confound would, of course, render moot the conclusions about the effects of conditions. Indeed, an analysis of category familarity in the first three studies examined revealed significant confounding of familiarity and conditions in two of the three studies.

Smith, Shoben, and Rips (1974) examined the latency to categorize a word as a member of a category which was a high-level superordinate (HLS) or a lowlevel superordinate (LLS) category (e.g., food, vegetable). The HLS and LLS categories were stibdivided into sets in which the exemplar to be categorized was associatively closer either to the LLS category (Set 1) or to the HLS category (Set 2). The mean frequency of Smith, Shoben, and Rips' (1974) categories, according to the present data, for their Set 1 categories (see Table 3 of their article) was 41.5 for HLS categories and 22.6 for LLS categories, and for their Set 2 categories it was 21.8 for HLS categories and 1.9 for LLS categories. Statistical evaluation of the differences showed that the frequency difference between levels was significant $[F(1,24)=14.38, p<.01]$, as was the difference between sets $[F(1,24)=6.49, p<.05]$, but that the frequency of levels and sets did not interact $(F<1.0)$. Obviously the "cards were stacked" against obtaining the conventional prediction for category size, that is, that HLS categories should require more time for processing than should LLS categories. In addition, the familiarity of Set 1 terms was considerably higher than that of Set 2 terms. While the familiarity differences do not explain away Smith, Shoben, and Rips' latency differences across sets, the present analysis shows that more was being varied across sets than just associative relationships. It seems that Smith, Shoben, and Rips' results do not pose as strong a challenge to previous findings on category size as they have been purported to do.

Another example of a confounding due to category familiarity can be found in a study by Loftus and Bolton (1974). In that study, subjects were required to generate either a superordinate of a category term (half of the trials) or a subordinate term (the remaining trials). Latency of generation was the dependent variable. As in the Smith, Shoben, and Rips (1974) experiment, category frequency was significantly greater for HLS category terms (36.5) than for LLS categories (18.4) (sign test, $\chi^{2}=4.5$, $\mathrm{df}=1, \mathrm{p}<.05$ ). No attempt will be made here to revise Loftus and Bolton's interpretations of their complex results, except to note the obvious-that their conclusions require revision due to the confounding of category familiarity with level of superordinate terms.

The studies of Smith, Shoben, and Rips and Loftus and Bolton have been cited here only because their complete presentation of method permitted quick access to their stimuli for evaluation of category familiarity. What proportion of previous studies suffer from the same defect is unknown. The third and last study examined here did not possess the categoryfamiliarity confound. Loftus, Freedman, and Loftus (1970) investigated the latency to name a subordinate of HHS and LLS categories. Category frequency did not approach being significantly different across HLS categories (27.7) and LLS categories (24.3).

Thus, whenever a category is nested under a particular variable (e.g., HLS-LLS, abstract-concrete, vague-precise, etc.), category familiarity should be controlled across conditions. The familiarity of category terms is important to research and theory for another reason as well. Ultimately, most theorists are concerned with typical language processing. The present norms permit assessment of a category as being or not being a "natural" language category. Since it has been shown here that many categories in most category norms are rare, if not artificial, investigators may wish to consider category familiarity in stimulus selection in future research. 
In summary, the present research demonstrates several important points. First, subjects can generate category terms just as they can generate words belonging to a category. Second, while categorization behavior is ubiquitous (Bruner, Goodnow, \& Austin, 1956), Table 1 suggests that the number of common lexical categories is finite and small. Third, categories vary in likelihood of being generated, that is, production frequency. Fourth, category-term production frequency may be inadvertently confounded with experimental conditions unless it is considered in stimulus selection. Fifth, in producing category terms, subjects cluster related terms in output, consistent with a higher order structure of categories in semantic memory. Finally, the present study has provided normative data which should be of value to researchers in permitting a choice of category stimuli according to familiarity level, as reflected by category-term production frequency.

\section{REFERENCE NOTE}

1. Cohen, B. H.. Bousfield, W. A., \& Whitmarsh, G. A. Cultural norms for verbal items in 43 categories. (Technical report No. 22). Storrs: University of Connecticut, Office of Naval Research, 1957.

\section{REFERENCES}

Battig, W. F.. \& Montague, W. E. Category norms for verbal items in 56 categories: $A$ replication and extension of the Connecticut category norms. Journal of Experimental Psychology, 1969, 80(3, Part 2).

Bousfield, W. A.. \& SEDGEwick, C. H. W. An analysis of sequences of restricted associative responses. Journal of General Psychology, 1944, 30, 149-165.

Bruner. J. S., Goodnow. J. J., \& Austin, G. A. A study of thinking. New York: Wiley, 1956.

Collen, A.. Wickens, D. D., \& Daniele, L. The interrelationship of taxonomic categories. Journal of Experimental Psychology: Human Leaming and Memory, 1975, 1, 629-633.

Collins. A. M.. \& Loftus. E. F. A spreading-activation theory of semantic processing. Psychological Review, 1975, 82, 407-428.

Hall, J. F. Verbal leaming and retention. Philadelphia: Lippincott, 1971.
Herrmann, D. J., Shoben, E. J., Klun, J. R., \& Smith, E. E. Cross-category structure in semantic memory. Memory \& Cognition, 1975, 3, 591-594.

Hunt, K. P., \& Hodge, M. H. Category-item frequency and category-name meaningfulness $(m)$ : Taxonomic norms for 84 categories. Psychonomic Monograph Supplements, 1971, 4(6, Whole No. 54).

KAuster, D. H. Psychology of verbal leaming and memory. New York: Academic Press, 1974.

Loess, H., Brown, A., \& Camprell, J. Cultural norms for verbal items in 30 taxonomic categories. Psychonomic Monograph Supplements, 1969, 3(7, Whole No. 39).

Loftus, E. F., \& Bolton, M. Retrieval of superordinates and subordinates. Journal of Experimental Psychology, 1974. 102, $121-124$

Loftus, E. F., Freedman, J. L.., \& Loftus, G. R. Retrieval of words from subordinate and superordinate categories in semantic hierarchies. Psychonomic Science, 1970, 21, 235-236.

Perfetti, C. A. Psychosemantics: Some cognitive aspects of structural meaning. Psychological Bulletin, 1972, 78, 241-259.

SHuEll, T. J. Clustering and organization in free recall. Psychological Bulletin, 1969, 72, 353-374.

SMrTh, E. E. Choice reaction time: An analysis of the major theoretical positions. Psychological Bulletin, 1968, 69, $77-110$.

Smith, E. E., Rips, L. J., \& Shoben, E. J. Semantic memory and psychological semantics. In G. E. Bower (Ed.), The psychology of learning and motivation: Advances in research and theory. New York: Academic Press, 1974.

Smith. E. E., Shoben, E. J., \& Rips, L. J. Comparison processes in semantic memory. Psychological Review, 1974, 81, 214-241.

Shapiro, S. I., \& Palermo, D. S. Conceptual organization and class membership: Normative data for representatives of 100 categories. Psychonomic Monograph Supplements, 1970, 3(11, Whole No. 43).

Tulving, E., \& Donaldson, W. Organization of memory. New York: Academic Press, 1972.

Wilkins, A. J. Conjoint frequency, category size, and categorization time. Journal of Verbal Learning and Verbal Behavior, 1971, 10. 382-385.

WOODWORTH, R. S., \& SCHLOSBERG, H. Experimental psychology. New York: Holt, 1954.

(Received for publication May 10, 1976; revision accepted August 9, 1976.) 